\title{
Optical laboratory facilities at the Finnish Meteorological Institute - Arctic Research Centre
}

\author{
Kaisa Lakkala ${ }^{1}$, Hanne Suokanerva ${ }^{1}$, Juha Matti Karhu ${ }^{1}$, Antti Aarva ${ }^{2}$, Antti Poikonen ${ }^{2}$, Tomi Karppinen ${ }^{1}$, \\ Markku Ahponen ${ }^{1}$, Henna-Reetta Hannula ${ }^{1}$, Anna Kontu ${ }^{1}$, and Esko Kyrö ${ }^{1}$ \\ ${ }^{1}$ Finnish Meteorological Institute - Arctic Research Centre, Tähteläntie 62, 99600 Sodankylä, Finland \\ ${ }^{2}$ Finnish Meteorological Institute, Observation Services, Helsinki, Finland \\ Correspondence to: Kaisa Lakkala (kaisa.lakkala@fmi.fi)
}

Received: 8 December 2015 - Published in Geosci. Instrum. Method. Data Syst. Discuss.: 18 January 2016

Revised: 20 May 2016 - Accepted: 23 May 2016 - Published: 25 July 2016

\begin{abstract}
This paper describes the laboratory facilities at the Finnish Meteorological Institute - Arctic Research Centre (FMI-ARC, http://fmiarc.fmi.fi). They comprise an optical laboratory, a facility for biological studies, and an office. A dark room has been built, in which an optical table and a fixed lamp test system are set up, and the electronics allow high-precision adjustment of the current. The Brewer spectroradiometer, NILU-UV multifilter radiometer, and Analytical Spectral Devices (ASD) spectroradiometer of the FMIARC are regularly calibrated or checked for stability in the laboratory. The facilities are ideal for responding to the needs of international multidisciplinary research, giving the possibility to calibrate and characterize the research instruments as well as handle and store samples.
\end{abstract}

\section{Introduction}

The location of the Finnish Meteorological Institute - Arctic Research Centre (FMI-ARC) $\left(67.367^{\circ} \mathrm{N}, 26.629^{\circ} \mathrm{E}\right)$ is ideal for atmospheric and environmental research in the boreal and sub-Arctic zone. Numerous international projects have been conducted in the FMI-ARC, and the need for multidisciplinary laboratory facilities have been obvious. In this paper, we present the optical laboratory facilities of the FMIARC and focus on the measurements of optical instruments used for stratospheric and climate research at the FMI-ARC.

The Brewer spectroradiometer (hereafter referred to simply as Brewer) measurements (Bais et al., 1993) started in 1988 at Sodankylä. First the focus was on total ozone measurements, as Sodankylä is affected by the springtime Arc- tic ozone loss in the stratosphere. Since 1990, the Brewer is also used to measure spectral solar ultraviolet (UV) irradiances. The Brewer is a single monochromator with a wavelength range from 290 to $325 \mathrm{~nm}$. The wavelength step of the recorded spectrum is $0.5 \mathrm{~nm}$. The slit function of the Brewer is $0.56 \mathrm{~nm}$ at full width at half maximum (FWHM). In 2012, a second Brewer was purchased to measure next to the old one on the roof of the sounding station of the observatory. The second Brewer is a double monochromator with a wavelength range from 290 to $365 \mathrm{~nm}$. The Brewer time series is one of the longest homogenized time series measured in the Arctic (Lakkala et al., 2003, 2008).

The long-term solar UV radiation is also measured with multichannel NILU-UV radiometers (Høiskar et al., 2003) located on the roof of the sounding station since 2007. In addition, the NILU-UV instruments have been set up to measure in the peatland field experiment and forest experiment of the Finnish Ultraviolet International Research Centre (FUVIRC) during the summers of 2002-2011 (Lakkala et al., 2016). The NILU-UV monitors the UV-B, UV-A, erythemally weighted (McKinlay and Diffey, 1987) UV radiation, photosynthetically active radiation (PAR), and total ozone column, and it provides information on cloudiness. The radiometer is a filter instrument with five UV channels, with central wavelengths around 305, 312, 320, 340, and $380 \mathrm{~nm}$ and bandwidths of around $10 \mathrm{~nm}$ at FWHM. The sixth channel measures the PAR in the 400-700 $\mathrm{nm}$ wavelength region. The radiometer has a Teflon diffuser, silicon detectors, and high-quality bandpass filters and is temperature-stabilized to $40^{\circ} \mathrm{C}$. One-minute averages of measured irradiances and detector temperature are recorded. 
The FieldSpec Pro JR Full Range spectroradiometer, manufactured by Analytical Spectral Devices (ASD), Inc., now known as PANalytical, measures solar UV spectrum in the wavelength region from 350 to $2500 \mathrm{~nm}$, covering the longer wavelengths of the UV part of the solar spectrum as well as the visible and near-infrared part of the solar spectrum. The measurements at FMI-ARC are used for validation of satellite measurements and algorithm development (e.g. Heinilä et al., 2014; Pulliainen et al., 2014; Niemi et al., 2012). The measurements started in 2006 and are located on a $30 \mathrm{~m}$ high tower (Sukuvaara et al., 2007), from which reflected radiation from both a forested and open area was measured until 2013. Currently only measurements over the forest are performed.

A common thing for these optical measurements is that the instruments' measurement capacity tends to change as a function of time. For example, the sensitivity of the channels of the multifilter radiometer tends to drift over time (Lakkala et al., 2005). In order to obtain reliable and homogenized measurements, the instruments need to be well characterized and regularly calibrated (Webb et al., 1998, 2003; Seckmeyer et al., 2001, 2010). The quality control and quality assurance of the measurements require monitoring of the stability of the instruments using regular lamp tests, which need to be performed in an appropriate optical laboratory. This work describes the characteristics of the optical laboratory facilities at the FMI-ARC and shows typical measurement protocols for the above-mentioned instruments.

\section{Laboratory facilities}

\subsection{Optical laboratory}

The optical laboratory was initially built in 1998 and moved to its present location in November 2002. It is a duplication of the optical laboratory at the FMI Jokioinen observatory. The laboratory comprises two adjacent rooms: the control room and the dark room. The temperature in the rooms is monitored using PT100 sensors, and both rooms are equipped with adjustable air conditioning. The floor is covered with a black plastic membrane, and the walls together with the ceiling lamps of the dark room are painted with antireflection black paint. Ceiling lamps are turned away from the measurement system. Lockers are covered with antireflection black cloths. An opening has been made on one wall of the dark room to serve as a lead-out for cables or installations which need outdoor air.

An optical table, from the manufacturer Melles Griot, is placed in the dark room. The average height from the floor is $91.5 \mathrm{~cm}$, and its dimensions are $100 \times 150 \mathrm{~cm}$. The lamp holders and needed sensors can be fixed to the table with high precision. A lamp holder is set up to fulfil the needs of the calibration of the Brewer spectroradiometer. Also UVB (BN-9102-147 UVB XB03) and UV-A (BN-9102-130
UVA XB05) sensors are set up in order to monitor the calibration lamp. The sensors are temperature-stabilized using circulating water.

The electronics of the laboratory include a $0.1 \Omega$ shunt resistor (Burster-1282-0.1), a high-precision digital multimeter (Hewlett Packard 3458A), a high-precision power supply (Hewlett Packard 6675A system DC power supply 0120V/0-18A), a voltage limiter (from 150 to $10 \mathrm{VDC}$ ), a voltage-to-voltage converter with galvanic isolation (Nokeval Signal Converter 641) (from 10 to 2.5 VDC with galvanic isolation), an adjustable voltage reference, a data logger (QLI50 Sensor Collector, manufactured by Vaisala Oyj), and a control PC. The mentioned electronics are located in the control room, and only the calibration lamp, the dark room temperature sensor, and the UV-B/A sensors are located in the dark room.

For absolute irradiance calibrations, the most important thing is controlling the current passing through the lamp. The lamp current is acquired by the voltage measurement over the reference shunt and controlled with the control room PC. The electrical circuit diagram of a calibration is shown in Fig. 1, where the main circuit is in bold. The system allows the current accuracy to be $\pm 0.001 \mathrm{~A}$. To ensure the accuracy, the multimeter and the shunt are sent every 12 years to SGS FIMKO Testing and Certification Services, Finland, for checking and calibration. During the last calibration (6-7 May 2014) the uncertainty of the shunt was $\pm 0.007 \%$, which makes $\pm 0.007 \Omega \mathrm{m}$. The reported uncertainty was based on a standard uncertainty multiplied by a coverage factor $k=2$, providing a level of confidence of approximately $95 \%$. The last calibration confirmed the specifications of the multimeter provided by the manufacturer, in which the accuracy of the voltage measurement over $24 \mathrm{~h}$ was $0.06 \mathrm{ppm}$.

LabVIEW System Design Software (LabVIEW), National Instruments, has been tailored to read the voltage drop of the shunt measured by the multimeter and to regulate the lamp current to the defined value. The regulation can be done in steps of $12 \mathrm{~mA}$ using the power supply (HP6675A). As there is a need for higher precision, an adjustable voltage reference with control voltage of $0-14 \mathrm{mV}$ is connected to the external analogue input of the power supply to finely tune the current regulation (Fig. 1).

In order to safely monitor the voltage over the lamp, which results from the current regulation, a voltage limiter and a voltage converter are needed to give the right input signal to the data logger. Galvanic isolation is made at the same time with the conversion. The voltage readings can be used to monitor the long-term stability of the lamp and for quality control of the measurements. The readings from the voltage converter, temperature, and UV-B/A sensors are transferred via the data logger to the control PC. 


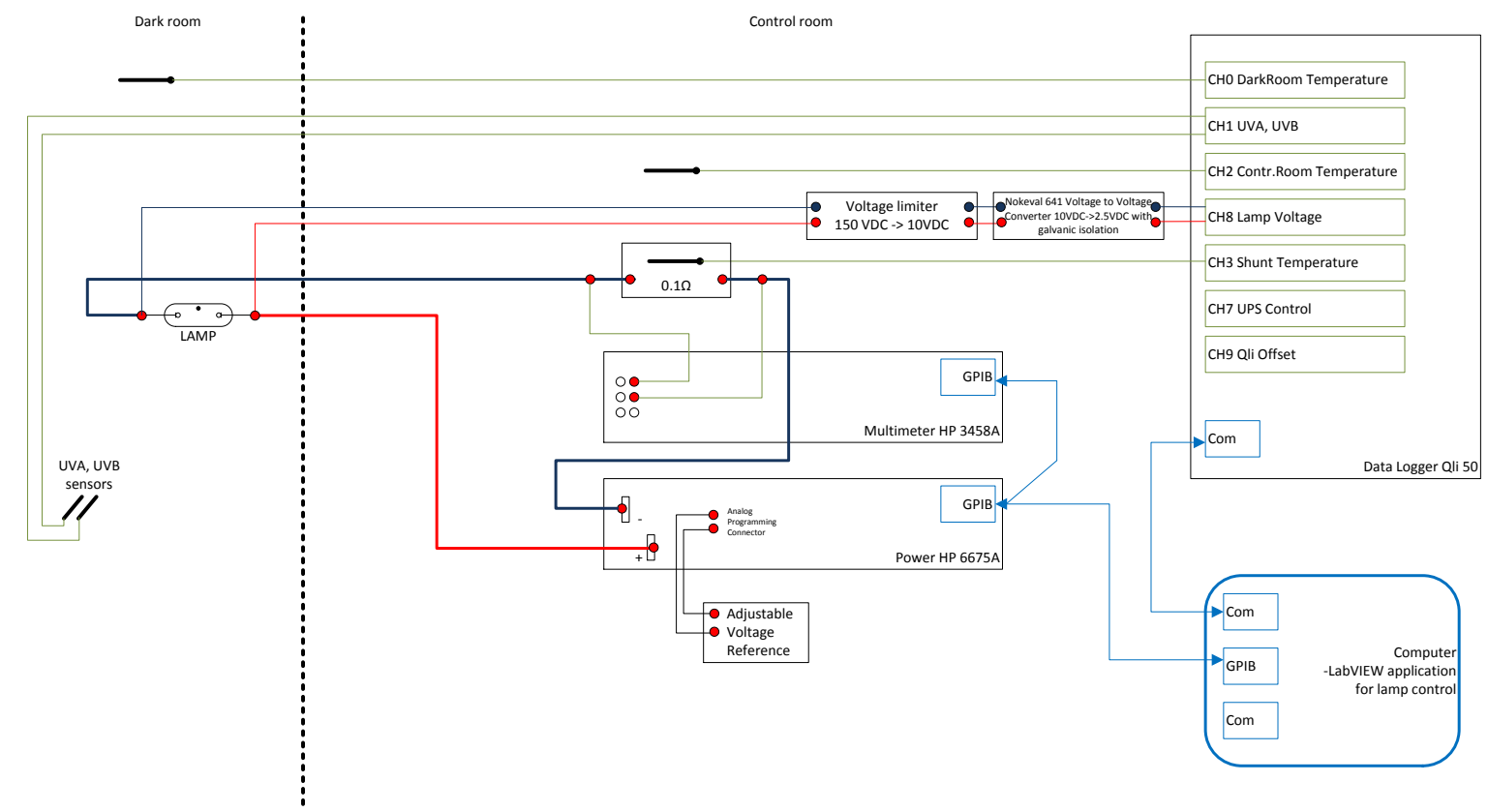

Figure 1. The electrical circuit of the optical laboratory in FMI-ARC. The main circuit is in bold. The vertical black dashed line denotes the separation between the dark room and the control room. Instruments on the left side are in the dark room, while the instruments on the right side are in the control room.

\subsection{Laboratory for biological studies}

The laboratory for biological studies is located in the next room of the optical laboratory. The room is equipped with machines needed, e.g., for snow and vegetation studies: a temperature chamber, a cold chamber, an ice cube maker, a fume hood, and a liquid nitrogen chamber.

The temperature in the temperature chamber (UT12, Thermo) can be regulated between ambient temperature $T\left(+20^{\circ} \mathrm{C}\right)$ and $+250^{\circ} \mathrm{C}$. The regulation range of the cold chamber (SRC 1812/3.1 B (L), Porkka) is between +2 and $+12{ }^{\circ} \mathrm{C}$, and its dimensions are $1800 \mathrm{~mm} \times 1200 \mathrm{~mm} \times 2000 \mathrm{~mm}$. The ice cube maker makes $21 \mathrm{~kg}$ of ice per $24 \mathrm{~h}$, and it can store $4 \mathrm{~kg}$ of ice. The volume of the liquid nitrogen chamber is $35 \mathrm{~L}$, the static working time is 130 days, the working time is 80 days, and the evaporation rate is $0.27 \mathrm{Lday}^{-1}$. The fume hood is manufactured by IS VET.

\section{Measurement procedures}

\subsection{UV spectroradiometer calibrations}

The response of the Brewer spectroradiometer is determined by performing $1000 \mathrm{~W}$ lamp measurements in the laboratory. The lamps are $1000 \mathrm{~W}$ tungsten-filament incandescent halogen lamps of type DXW operated in vertical orientation. The bulbs have been installed in their sockets by Gigahertz Optik. A primary standard is used to transfer the calibration from the National Standard Laboratory MIKES-Aalto. Using the measurements of the Brewer, the irradiance scale is transfered to working standards, which are used for the calibration of the Brewer every 6 weeks. The procedure is described in more detail in Mäkelä et al. (2016) and Lakkala et al. (2008).

Before a calibration the Brewer is moved inside the dark room usually the day before. The multimeter is switched on then, which allows both the Brewer and the multimeter to stabilize around $15 \mathrm{~h}$ before a calibration. The Brewer is placed on a trolley, which can be fixed and levelled in exactly the same place each time. The Brewer and the lamp were aligned under the same vertical optical axis by using an alignment jig and laser. The distance between the diffuser of the Brewer 


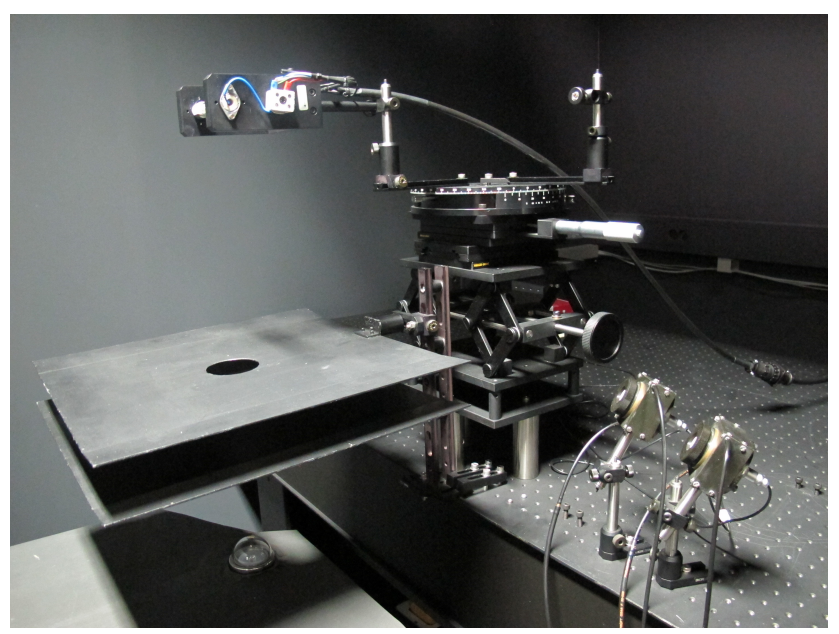

Figure 2. Lamp measurement with the Brewer spectroradiometer. The diffuser of the Brewer is in the bottom left corner under the baffles. The lamp is placed in the lamp holder over the baffles. The goniometer is seen in the middle, and the UV-A and UV-B sensors in the bottom right corner.

and the lamp is set to $50 \mathrm{~cm}$. Two baffles are used between the lamp and the Brewer in order to reduce the effect of stray light. The measurement arrangements are shown in Fig. 2.

During a lamp measurement, the current is set to $8 \mathrm{~A}$, with an accuracy of $\pm 0.001 \mathrm{~A}$. The current is controlled by the LabVIEW program, which allows the current to increase slowly for $2-3$ min before reaching the final level. After measurements the current goes down slowly. The lamps typically need $15-20 \mathrm{~min}$ to stabilize before a measurement can start. The measurement itself takes around 17 min when scanning up to $365 \mathrm{~nm}$. After the measurement, the lamp is left untouched until it has cooled down to near room temperature. The temperature of the control and dark rooms is set to $23^{\circ} \mathrm{C}$. The ventilation is on during the warming of the lamps but turned off during the measurements in order to avoid airflows around the lamp. The current, voltage, and room temperatures are recorded in a separate metadata file for each measurement. The intensity of the lamp is recorded using the UV-B and UV-A sensors of the laboratory, so that sudden changes can be noticed.

\subsection{Stability of the multifilter UV instruments}

The fixed set-up of the optical laboratory is also used for performing the stability checks of the NILU-UV multichannel radiometers of the FMI-ARC. As routine procedure, the stability of the channels of the NILU-UV is checked twice a year: in spring and in autumn. One-hundred-watt $(100 \mathrm{~W})$ OSRAM Radium lamps are mounted in lamp units produced by the manufacturer of the NILU-UV instrument. The lamp unit is connected to the circuit in the place of the lamp (Fig. 1). At least five lamps are used in order to detect the drift of the lamp from the drift of the instrument.

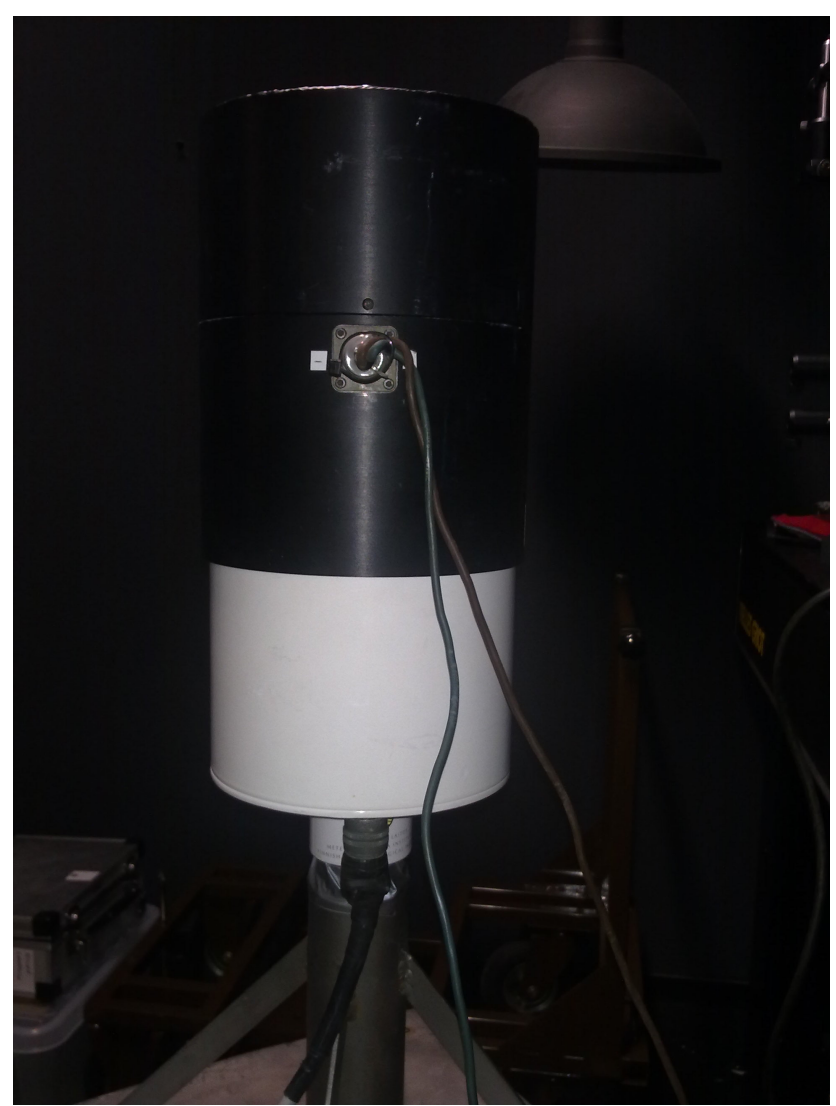

Figure 3. Lamp measurement of the NILU-UV radiometer. The NILU-UV is the white cylinder. The lamp is placed inside the black cylinder on the top of the NILU-UV.

The lamp is warmed up during $5 \mathrm{~min}$ in the dark box of the lamp unit at the side of the radiometer. If the lamp were warmed up at its measurement position on the top of the diffuser, the warming of the radiometer would affect the measurements (Lakkala et al., 2005). The current is increased slowly and set to $6 \mathrm{~A}$ by the operator. After the warming, the dark box including the lamp is placed above the diffuser, giving a vertical beam exactly to the same point of the diffuser during each measurement (Fig. 3). The data are recorded with a time step of $1 \mathrm{~s}$ for around $20 \mathrm{~s}$, after which the dark box is removed from the diffuser and the lamp is left to cool down back to the room temperature.

\subsection{Stability of the UV-VIS spectrometer}

The fixed set-up of the optical laboratory is also used for monitoring the stability of the ASD field spectroradiometer and a Spectralon reference plate. The Spectralon reference plate is used as a reference for reflection measurements. The lamp measurements are performed once a year with similar $1000 \mathrm{~W}$ tungsten-filament incandescent halogen lamps of type DXW operated in vertical orientation as used for the calibration of the Brewer spectroradiometers (see Sect. 3.1). 


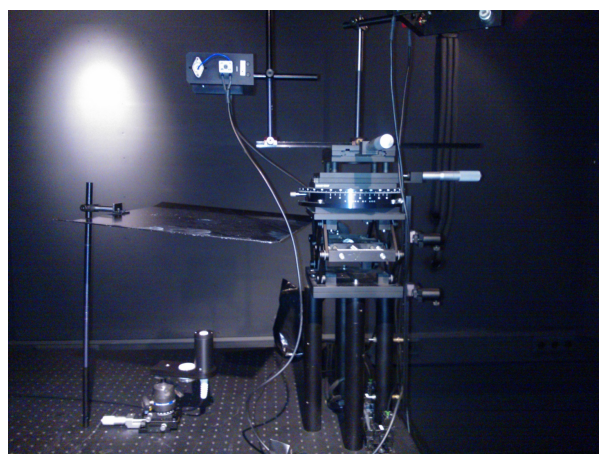

Figure 4. The remote cosine receptor measurement with the ASD FieldSpec Pro JR spectroradiometer.The entrance of the cosine receptor is the small white spot on the top of the black cylinder straight under the lamp. The light spot on the wall is reflection from the laboratory light, which is off during the measurements.

The calibration of the lamp is traceable to the National Standard Laboratory MIKES-Aalto.

Before the measurements, the ASD spectroradiometer is left to stabilize for at least half an hour in the room temperature. To monitor the stability of the ASD spectroradiometer, and to separate changes in the Spectralon plate from the changes in the spectroradiometer in the reflectance measurement, the spectrum of the lamp is measured with the remote cosine receptor (RCR). The RCR is fixed on the optical table at a vertical distance of $49 \mathrm{~cm}$ from the lamp (Fig. 4). One baffle is used to avoid stray light. Reflectance measurements of the Spectralon plates are used for monitoring of the changes in the field Spectralon plate and in the ASD spectroradiometer itself. Since the field Spectralon is subject to, e.g., dust, dirt, snow, rain, freezing, and mechanical stress from continuous use, its properties change. Both the field Spectralon plate and a reference Spectralon plate stored in laboratory conditions are measured. In the reflectance measurements the fibre optic cable is attached to a pistol grip fixed to the table, and the Spectralon plate is set in a fixed position. This set-up allows the fibre optic cable to be pointed to exactly the same spot on the Spectralon plates each time. The alignment is adjusted so that the radiation from the lamp is reflected from a Spectralon plate to the fibre optic cable (Fig. 5). The distance between the plate and the lamp is set to $65 \mathrm{~cm}$.

\section{Conclusions}

The optical laboratory facilities at the FMI-ARC comprise a control room, a dark room, a facility for biological studies, and an office. They are ideal for calibration and characterization of optical instruments such as spectroradiometers, broadband and multichannel radiometers, and aurora cameras. The facilities promote the possibilities for multidisciplinary research. Several international groups have per-

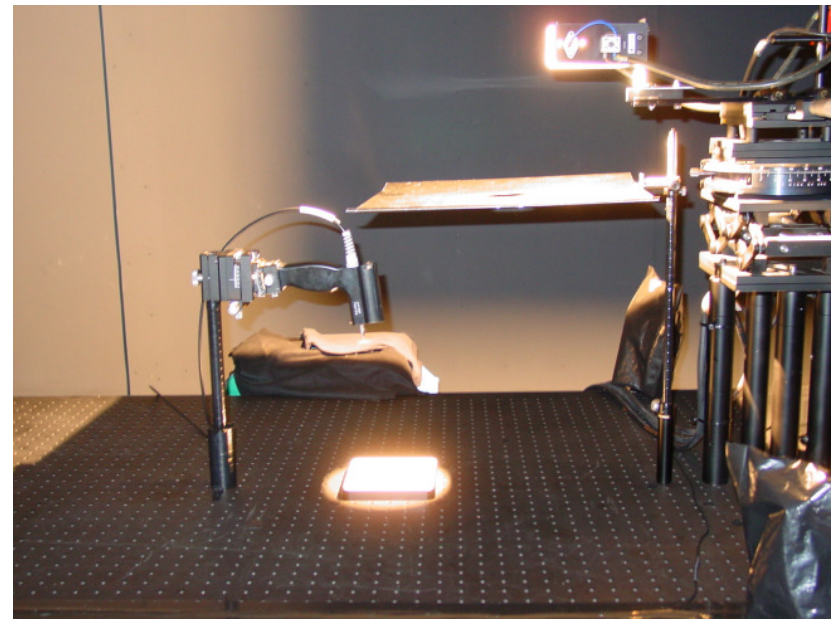

Figure 5. The reflectance measurement of the Spectralon reference plate with the ASD FieldSpec Pro Jr spectroradiometer. The reference plate in placed on the table, and the fibre optic cable is attached to the pistol grip fixed to the table in order to measure the reflected lamp radiation. The lamp is attached to the holder in the top right corner.

formed studies at FMI-ARC and used the facilities for stratospheric, snow, vegetation, and ionospheric studies during the Lapland Atmosphere - Biosphere Facility (LAPBIAT) project under the Improving Human Research Potential Access to Research Infrastructures of the European Union (contract no. 025969-TA, http://www.sgo.fi/lapbiat). The facilities have served as a central research infrastructure of the Finnish Ultraviolet International Research Center (FUVIRC), where biologists could properly handle and store their samples.

In this work, we presented the set-up for calibration of the Brewer spectroradiometers and measuring the stability of the ASD spectroradiometer and the NILU-UV multichannel radiometers of the FMI-ARC. The facilities have also been used for characterizations of the instruments; e.g. the temperature and cosine response characterization of the Brewer spectroradiometer have been done in the dark room. Also the aurora cameras of the FMI's network are calibrated in the dark room. The stability of the travelling reference instrument of the NILU-UV Antarctic network was measured once a year in the optical laboratory (Lakkala et al., 2005).

In the dark room, a fixed set-up is made for vertical optical axis $1000 \mathrm{~W}$ DXW lamp measurements, and the electronics allow precise regulation of the current. The optical table is large enough for customized set-up for different optical instruments, and the rooms have enough space for temporary instruments in order to welcome research groups with different needs. 
Acknowledgements. Tapani Koskela is acknowledged for the original design of the optical laboratory.

Edited by: N. Partamies

\section{References}

Bais, A., Zerefos, C., Meleti, C., Ziomas, I., and Tourpali, K.: Spectral measurements of Solar Radiation and its Relation to Total Ozone, $\mathrm{SO}_{2}$ and Clouds, J. Geophys. Res., 98, 5199-5204, 1993.

Heinilä, K., Salminen, M., Pulliainen, J., Cohen, J., Metsämäki, S., and Pellikka, P.: he effect of boreal forest canopy to reflectance of snow covered terrain based on airborne imaging spectrometer observations, Int. J. Appl. Earth Obs. Geoinf., 27, 31-41, 2014.

Høiskar, B., Haugen, R., Danielsen, T., Kylling, A., Edvardsen, K., Dahlback, A., Johnsen, B., Blumthaler, M., and Schreder, J.: Multichannel moderate-bandwidth filter instrument for measurement of the ozone-column anount, cloud transmittance, and ultraviolet dose rates, Appl. Optics, 42, 3472-3479, 2003.

Lakkala, K., Kyrö, E., and Turunen, T.: Spectral UV Measurements at Sodankylä during 1990-2001, J. Geophys. Res., 108, 4621, doi:10.1029/2002JD003300, 2003.

Lakkala, K., Redondas, A., Meinander, O., Torres, C., Koskela, T., Cuevas, E., Taalas, P., Dahlback, A., Deferrari, G., Edvardsen, K., and Ochoa, H.: Quality assurance of the solar UV network in the Antarctic, J. Geophys. Res., 110, D15101, doi:10.1029/2004JD005584, 2005.

Lakkala, K., Arola, A., Heikkilä, A., Kaurola, J., Koskela, T., Kyrö, E., Lindfors, A., Meinander, O., Tanskanen, A., Gröbner, J., and Hülsen, G.: Quality assurance of the Brewer spectral UV measurements in Finland, Atmos. Chem. Phys., 8, 33693383, doi:10.5194/acp-8-3369-2008, 2008.

Lakkala, K., Jaros, A., Aurela, M., Tuovinen, J.-P., Kivi, R., Suokanerva, H., Karhu, J., and Laurila, T.: Radiation measurements at the Pallas-Sodankylä Global Atmosphere Watch station - diurnal and seasonal cycles of ultraviolet, global and photosynthetically-active radiation, Boreal Environ. Res., 21, 427-444, 2016.

Mäkelä, J. S., Lakkala, K., Meinander, O., Kaurola, J., Koskela, T., Karhu, J. M., Karppinen, T., Kyrö, E., de Leeuw, G., and Heikkilä, A.: In search of traceability: two decades of calibrated Brewer UV measurements in Sodankylä and Jokioinen, Geosci. Instrum. Method. Data Syst. Discuss., doi:10.5194/gi-2015-40, in review, 2016.
McKinlay, A. F. and Diffey, B. L.: A reference action spectrum for ultraviolet induced erythema in human skin, CIE Research Note, CIE J., 6, 17-22, 1987.

Niemi, K., Metsämäki, S., Pulliainen, J., Suokanerva, H., Böttcher, K., Leppäranta, M., and Pellikka, P.: The behaviour of mastborne spectra in a snow-covered boreal forest, Remote Sens. Environ., 124, 551-563, doi:10.1016/j.rse.2012.06.008, 2012.

Pulliainen, J., Salminen, M., Heinilä, K., Cohen, J., and Hannula, H.-R.: Semi-empirical modeling of the scene reflectance of snow-covered boreal forest: validation with airborne spectrometer and lidar observations, Remote Sens. Environ., 155, 303-311, 2014.

Seckmeyer, G., Bais, A., Bernhard, G., Blumthaler, M., Booth, C., Disterhoft, P., Eriksen, P., McKenzie, R., Miyauchi, M., and Roy, C.: Instruments to Measure Solar Ultraviolet Radiation, Part 1: Spectral Instruments, Global Atmosphere Watch Report No. 125, World Meteorological Organization (WMO), Geneva, 30 pp., 2001.

Seckmeyer, S., Bais, A., Bernhard, G., Blumthaler, M., Johnsen, B., Lantz, K., and McKenzie, R.: Instruments to Measure Solar Ultraviolet Radiation, Part 3: Multi-channel filter instruments, Global Atmosphere Watch Report No. 190, World Meteorological Organization (WMO), Geneva, 51 pp., 2010.

Sukuvaara, T., Pulliainen, J., Kyrö, E., Suokanerva, H., Heikkinen, P., and Suomalainen, J.: Reflectance spectroradiometer measurement system in 30 meter mast for validating satellite images, IGARSS: 2007 IEEE International Geoscience and Remote Sensing Symposium, 23-28 July 2007, Barcelona, 2885-2889, 2007.

Webb, A., Gardiner, B., Martin, T., Leszcynski, K., Metzdorf, J., and Mohnen, V.: Guidelines for Site Quality Control of UV Monitoring, Global Atmosphere Watch Report No. 126, World Meteorological Organization (WMO), Geneva, 39 pp., 1998.

Webb, A., Gardiner, B., Leszczynski, K., Mohnen, V., Johnston, P., Harrison, N., and Bigelow, D.: Quality Assurance in Monitoring Solar Ultraviolet Radiation: the State of the Art, Global Atmosphere Watch Report No. 146, World Meteorological Organization (WMO), Geneva, 45 pp., 2003. 